\title{
Weight Gain after Smoking Cessation
}

\author{
F. Pistelli1,2, F. Aquilini1, L. Carrozzi1,2
}

ABSTRACT: Weight Gain after Smoking Cessation. F. Pistelli, F. Aquilini, L. Carrozzi.

Both overweight or obesity and cigarette smoking are relevant risk factors for public health. Cigarette smoking is associated with lower body weight while smoking cessation is associated with weight gain. Most smokers who quit experience a weight gain, particularly within one year, and it may persist up to 8 years after smoking cessation. However, only a minority of quitters gain excessive weight. Some individual characteristics have been found to be associated with excessive weight gain after smoking cessation while methodological problems may affect estimates of weight gain observed in different studies. Main mechanisms to explain weight gain after smoking cessation include increased energy intake, decreased resting metabolic rate, and decreased physical activity. The health benefits of smoking cessation far exceed any health risks that may result from smoking cessation-induced body weight gain. As weight gain may be a barrier against quitting smoking or a reason to restart smoking, behavioural and pharmacological methods have been evaluated to control weight gain after smoking cessation. Physicians should apply efficient strategies to promote smoking cessation on their weight-concerned smoking patient. This review briefly addresses some issues on the relationship between smoking cessation and weight gain, with regard to the size of the problem, mechanisms, health risks and control strategies.

Monaldi Arch Chest Dis 2009; 71: 2, 81-87.

Key words: Smoking cessation, Weight gain, Body mass index, Nicotine withdrawal symptoms, Gender-related differences.

1 UO Pneumologia e Fisiopatologia Respiratoria 1 Universitaria, Dipartimento Cardiotoracico, Azienda OspedalieroUniversitaria Pisana, Pisa,

2 Unità di Epidemiologia Ambientale Polmonare, Istituto di Fisiologia Clinica CNR, Pisa, Italy.

Correspondence: Francesco Pistelli, Unità di Epidemiologia Ambientale Polmonare, Istituto di Fisiologia Clinica CNR, Via Trieste 41, 56126 Pisa, Italy; e-mail francesco.pistelli@ifc.cnr.it

\section{Introduction}

Both overweight or obesity and cigarette smoking are relevant risk factors for public health, being associated with an increased risk of death [1, 2]. Epidemiological data indicates that the prevalence of overweight and obesity has doubled or tripled in the past few decades in the US, in Europe, and even in many developing countries [3]. According to estimates from the National Health and Nutrition Examination Survey (NHANES), a nationally representative sample of the US population, in 20032004 the prevalence of overweight or obesity (Body Mass Index $\left.(\mathrm{BMI}) \geq 25 \mathrm{~kg} / \mathrm{m}^{2}\right)$ in adults aged 20 years or older was $66.3 \%$ [4].

Cigarette smoking is associated with lower body weight while smoking cessation is associated with weight gain [5-8]. Weight gain may be a barrier against quitting smoking, a reason to restart smoking or a risk for health problems. This review briefly addresses some issues on the relationship between smoking cessation and weight gain, with regard to the size of the problem, mechanisms, health risks and control strategies.

\section{The size of the problem}

Amount of weight gain and likelihood of gaining weight after smoking cessation

In 1990, the US Surgeon General published a landmark report on The Health Benefits of Smok- ing Cessation, which included a chapter on smoking cessation and body weight change [6]. Based on 15 longitudinal studies conducted between 1970-1990, with a median follow-up of 2 years and an average sample size of 1348 subjects, the average weight gain after smoking cessation was about $2.3 \mathrm{~kg}$, ranging between 0.74 and $5.15 \mathrm{~kg}$. Overall, in five reviewed studies, the risk of weight gain after cessation was $45 \%$ (mean 1.45 , range 1.31-1.75) greater for quitter than for continuing smokers. The report concluded that approximately $80 \%$ of smokers who quit gain weight after cessation, but only about $3.5 \%$ of those who quit smoking gain more than $9 \mathrm{~kg}$ [6].

Data from the third NHANES study [7], conducted from 1988 through 1991, has shown that the weight gain among smokers who quit that was in excess of the gain among continuing smokers was $4.4 \mathrm{~kg}$ for men and $5.0 \mathrm{~kg}$ for women over a 10 -year period. $16 \%$ of the men and $21 \%$ of the women who had quit smoking within the past 10 years gained $15 \mathrm{~kg}$ or more. Quitters were significantly more likely to become overweight than those who had never smoked (OR 2.42, 95\% C.I. $1.02-5.775$ for men, and OR 2.02, 95\% C.I. 1.043.94 for women).

Among participants in the Lung Health Study [8], a randomised clinical trial of smoking cessation on middle-aged volunteers with asymptomatic airway obstruction, men who achieved sustained quitting for 5 years gained a mean of $4.9 \mathrm{~kg}$ in the first year and a mean of $2.6 \mathrm{~kg}$ over the 5 -year fol- 
low-up, while corresponding figures for women were $5.2 \mathrm{~kg}$ and $3.4 \mathrm{~kg}$, respectively. Also, among sustained quitters, $7.6 \%$ of men and $19.1 \%$ of women gained $\geq 20 \%$ of baseline weight; $60 \%$ of the gain occurred in year 1, although significant weight gains continued through year 5. Over one third of those who sustained smoking cessation for 5 years gained $>10 \mathrm{~kg}$.

In a sample of 7124 residents of Germany aged 18-79 years from a national health examination survey [5], adjusted OR of the risk for former (> 12 months) smokers of 20 cigarettes per day to become overweight (BMI $\geq 25 \mathrm{~kg} / \mathrm{m}^{2}$ ) or obese $\left(\mathrm{BMI} \geq 30 \mathrm{~kg} / \mathrm{m}^{2}\right)$ was 1.7 and 2.3 in males, and 1.4 and 1.1 in females, respectively, as compared to never smokers. The proportions of overweight or obesity ranged from 78.7 to $91.1 \%$ and from 51.9 to $64.3 \%$ among male and female former smokers, respectively, depending on the number of cigarettes smoked per day.

The mean increase in waist circumference after smoking cessation has been reported in a population-based study in Copenhagen: an increase $\geq 5 \mathrm{~cm}$ was observed in $42 \%$ of the quitters, and it was 3.88 $\mathrm{cm}( \pm 5.4 \mathrm{~cm})$ higher in females than in males [9].

With regard to the trend over time, evidence suggests that weight gain is greater within one year [8] and even in the 1-2 months following cessation [10]. In the long term, population-based data from the third NHANES study showed that quitters within the past 10 years prior the examination were significantly more likely than never smokers to remain overweight (OR 1.50, 95\% C.I. 0.474.85 for men, and OR 1.45, 95\% C.I. 0.54-3.92 for women) [7]. In a cohort $(\mathrm{n}=1532)$ of treatmentseeking heavy smokers ( $\geq 15$ cigarettes per day) participating in a double-blind randomised placebo-controlled trial with nicotine transdermal patch, an increase in BMI $\left(2.5 \mathrm{~kg} / \mathrm{m}^{2}\right.$ more on average vs. baseline) persisted up to 8 years after smoking cessation [11]. In a cross-sectional study, it was observed that heavy smokers $(\geq 25$ cigarettes per day), after experiencing large weight gain in the few years after smoking cessation, thereafter lose weight to the never smoker level, while light and moderate smokers gain weight up to the neversmoker level without any excess after smoking cessation [12].

\section{Methodological issues}

We selected relevant references on weight gain after smoking cessation by using the PubMed searching engine of the United States National Library of Medicine and the National Institutes of Health (URL: www.pubmed.org). A manual search starting from selected references was also performed. No systematic selection procedure was applied. Those large, population-based, longitudinal studies or large clinical trials from United States and Europe were preferably selected.

In order to correctly interpret data on weight gain after smoking cessation, some general methodological issues should be taken into account. The magnitude of the weight gain varies ac- cording to the study population, while it could also be related to the increase of weight observed in the general population. There are few studies designed specifically to assess the effect of smoking cessation on weight gain prospectively. Existing studies may have methodological problems, including limited follow-up periods, the use of selfreported height and weight, failure to biochemically validate smoking status, and a tendency to report point prevalence instead of continuous abstinence.

\section{Characteristics associated with excessive weight gain after smoking cessation}

Smokers gaining excessive weight after smoking cessation may differ from those who do not gain weight. Several individual characteristics should be considered, including gender, age, race, number of cigarettes smoked per day before cessation, weight history, comorbidity, life styles such as eating patterns and physical activity, or concerns about post-cessation weight gain.

Subjects younger than 55 years old, smokers of $\geq 25$ cigarettes per day, and those with low socioeconomic status has been associated to higher weight gain $[10,13,14]$. Most studies report that women tend to gain more weight than men [7-9, 14], but in other studies an opposite figure has been found $[5,15]$. Longitudinal data from the National Academy of Sciences-National Research Council Twin Registry [14] has shown that weight change was significantly greater in monozygotic than dizygotic pairs in which both twins quit smoking, suggesting that underlying genetic factors may influence weight changes. In this study, super-gainers were significantly younger, with a lower socio-economic status, and differed on a number of health habits before quitting, including physical activity, alcohol consumption and other diet habit.

\section{Mechanisms}

Although there is convincing evidence for the association between smoking and lower body weight, underlying mechanisms are not clear. Nicotine may be involved in feeding behaviour by influencing the levels and expression of many peptide hormones and neurotransmitters, including leptin (negative regulator of food intake and a positive regulator of energy expenditure), neuropeptide Y (stimulator of feeding), orexins (positive regulators of food intake), noradrenaline (stimulator of food ingestion), dopamine and serotonin (inhibitors of food ingestion) [16].

Effects of cigarette smoking on adipose tissue metabolism have also been evaluated. It has been observed that fat oxidation increases with increasing nicotine uptake [17] and smoking cessation is associated with increases in lipoprotein lipase activity in adipose tissue, which contribute to weight gain after smoking cessation [18]. On the other hand, it has been shown that cigarette smoking stimulates lipolysis without increasing oxidation 
of fat and that smoking cessation does not result in a rebound tendency to synthesis or storage of fat, both under controlled eucaloric dietary conditions [19] and even in the presence of positive shortterm energy balance [20].

Main mechanisms that have been evaluated to explain weight gain after smoking cessation include increased energy intake, decreased resting metabolic rate, and decreased physical activity. However, it has been also observed that lower BMI of smokers compared to non-smokers reflects the personality characteristics of those who choose to smoke and that the tendency to gain weight after smoking cessation may have behavioural rather than tobacco-related pharmacological explanations [21]. Further research is needed in this field.

Increases in food intake and decreases in resting energy expenditure are largely responsible for weight gain after smoking cessation, while change in physical activity does not play a role in either differences in body weight between smokers and nonsmokers or the weight gain associated with smoking cessation [6]. Among studies reviewed in the 1990 Surgeon General report, large individual differences in subjects' dietary and metabolic changes after smoking cessation were demonstrated. Most short-term evaluations (e.g. 3 days or less) found that food intake, particularly the consumption of sweet foods and simple carbohydrates, increases after smoking cessation. Prospective investigations found that both self-reported and quantified food intake changes over time increased among subjects after quitting. In a quoted comprehensive evaluation of change in energy balance, analysing changes in food intake, physical activity, and resting metabolic rate in 13 sedentary females who quit smoking for 48 days, mean daily food intake increased by $177 \mathrm{kcal}$ and explained $69 \%$ of the variance in changes in weight (1.84 $\mathrm{kg}$ ), while no changes in physical activity or resting metabolic rate were observed [22].

Even in subsequently published studies, contrasting results have been reported on decreased resting metabolic rate as mechanisms partly explaining weight gain after smoking cessation, with the mean resting metabolic rate reduction ranging between $4 \%$ and $16 \%$ and accounting for less than $40 \%$ of the weight gain [16]. In a clinical trial that monitored dietary intake and had biochemically validated smoking status over 5 years (Multiple Risk Factor Intervention Trial), weight gain continued after quitting smoking despite decreases in caloric intake [23].

\section{Changes in weight-related health risks after smoking cessation}

The health benefits of smoking cessation far exceed any health risks that may result from smoking cessation-induced body weight gain. This affirmation has been initially supported by studies demonstrating that individuals who quit smoking and gain weight experienced relatively small changes in health-related risk factors such as blood pressure, serum cholesterol and blood glucose [6]. Indeed, some of the potentially adverse effects of weight gain on health risks are mitigated by the reduction of the risk of cardiovascular problems. For example, according to reviewed evidence [16], in spite of the weight gain, smoking cessation seems to improve insulin sensitivity and is associated with an increase in high density lipoprotein cholesterol, while it is associated with a gradual normalisation of blood and plasma viscocities, haematocrit, blood cell filter ability, plasma fibrinogen levels as well as total white cell count.

Only those smokers who have large weight gain after smoking cessation would experience important changes in weight related risk factors, and the proportion of ex-smokers who gain large amounts of weight (e.g. more than $10 \mathrm{~kg}$ ) is small [6]. It should be noted that these figures might be revisited over time, if it is taken into account that mean BMI tends to increase in the general population.

Consistently with other longitudinal studies, in an Italian general population sample, we showed that weight gain over time affects lung function independently of age, occupational exposure and also smoking habit reported at baseline [24, 25]. Those longitudinal studies that have assessed the relation of change in lung function to smoking cessation and change in BMI have shown that the beneficial effect of smoking cessation outweighs the adverse effect of weight gain [26-28]. For example, according to estimates based on data from the Lung Health Study, a person who quit smoking would have to gain about $60 \mathrm{~kg}$ or $38 \mathrm{~kg}$ of weight to have the same effect of 5 years changes in forced expiratory volume in one second $\left(\mathrm{FEV}_{1}\right)$ or in forced vital capacity, respectively, as continuing to smoke.

The net effect of both smoking cessation and weight gain on lung function in a population-based study has been evaluated among participants in the European Community Respiratory Health Study [29]. The authors found a similar net effect of smoking cessation in men and women, but a greater decline in lung function due to weight gain in men: the $\mathrm{FEV}_{1}$ changed by $-11.5 \mathrm{~mL}(-13.3$ to 9.6) per $\mathrm{kg}$ of weight gained in men, and by -3.7 $\mathrm{mL}$ per $\mathrm{kg}(-5.0$ to -2.5$)$ in women, which diminished the benefit of quitting by $38 \%$ in men, and by $17 \%$ in women.

\section{Control strategies}

Smoking may be used as a means of weight control, especially by younger adults [30], and weight gain after smoking cessation is of concern to many cigarette smokers, particularly women $[31,32]$. Even in the context of poor health and limited physical functioning, smokers have been found to be concerned about weight gain after quitting [33]. There are several weight-related smoking variables that characterise weight-concerned smokers, including: importance of weight as a factor in smoking initiation; smoking as a weight control strategy; increased appetite and weight gain as withdrawal symptoms; willingness 
to quit to gain weight; self-efficacy about relapse in the face of weight gain; readiness to quit smoking; preoccupation with body image - rather than weight gain $[32,34]$. Also pregnant women who are more concerned about post-cessation weight gain may be less likely to quit smoking during pregnancy or remain abstinent in the postpartum period [35]. It has been also hypothesised that weight gain and weight concerns are independent factors, as daily smokers were found to be significantly less concerned about their weight than never-smokers, and neither weight concerns nor eating patterns were predictive of point abstinence at 1-year follow-up, in a Danish general population sample of more than 6000 adults aged 30-60 years [36].

Strategies that successfully moderate weight gain after smoking cessation may encourage weight-conscious smokers to attempt cessation and may facilitate the efforts of successful quitters to remain abstinent. Behavioural and pharmacological methods have been evaluated to reduce weight gain after smoking cessation.

There is no convincing evidence that counselling interventions specifically designed to mitigate weight gain during a quit attempt result in reduced weight gain $[37,38]$, and smoking cessation programmes that include a weight control component have not successfully increased smoking cessation [6]. Also, simultaneously dieting and quitting has been observed to undermine attempts to quit smoking [39, 40]. A different approach, i.e. to combat the weight concerns themselves rather than the weight gain, has been shown to be efficient. In a group of weight-concerned women, cognitive-behavioural therapy to reduce weight concern while discouraging dieting improved smoking cessation outcome compared to a behavioural weight control programme to prevent weight gain [41]. In observational studies [42] and randomised trials [43] it has been observed that physical activity at the time of smoking cessation can lessen the weight gain associated with quitting. Evidence suggests that relatively small doses of exercise should be recom- mended also as an aid to managing cigarette cravings and withdrawal symptoms [44].

With regard to the pharmacological methods, according to 2008 update of US Guidelines on Treating Tobacco Use and Dependence, for smokers who are greatly concerned about weight gain, it may be most appropriate to prescribe or recommend bupropion SR or nicotine replacement therapy (NRT) (in particular, nicotine gum $4 \mathrm{mg}$ and nicotine lozenge $4 \mathrm{mg}$ ), which have been shown to delay weight gain after quitting (strength of evidence B) [45].

A number of other pharmacological approaches have been evaluated. In three studies satisfying criteria for a Cochrane systematic review was found that Rimonabant $20 \mathrm{mg}$, a selective type 1 cannabinoid receptor antagonist, may increase the odds of quitting approximately 1(1/2)-fold and moderate weight gain in the long term [46]. Preliminary results suggest that combining naltrexone and bupropion may help minimise post-cessation weight gain [47]. Some evidence has shown that weight gain can be minimised to some degree by serotoninergic drugs such as fluoxetine [48, 49].

From a clinical viewpoint, the physician should neither deny the likelihood of weight gain nor minimise its significance to the patient. Rather, the physician should inform the patient about the likelihood of weight gain and prepare the patient for its occurrence. Clinician statements to help a patient prepare for and cope with weight gain after quitting recommended in the 2008 update Guidelines on Treating Tobacco Use and Dependence are reported in table 1 [45].

\section{The experience of the Smoking Cessation Clinic of the University Hospital of Pisa (Italy)}

As an example of what can be observed in the real life of a clinical routine, we present some data on weight gain observed in smokers following a physician-assisted smoking cessation programme within the Smoking Cessation Centre of the University Hospital of Pisa (Italy). This is a clinic op-

Table 1. - Clinician statements to help a patient prepare for and cope with weight gain after smoking cessation. From 2008 update Guidelines on Treating Tobacco Use and Dependence [45]

The great majority of smokers gain weight once they quit smoking. However, even without special attempts at dieting or exercise, weight gain is usually $4.5 \mathrm{~kg}$ or less.

Some medications, including bupropion SR and nicotine replacement medicines, may delay weight gain.

There is evidence that smokers often gain weight once they quit smoking, even if they do not eat more. However, there are medications that will help you quit smoking and limit or delay weight gain. I can recommend one for you.

The amount of weight you will likely gain from quitting will be a minor health risk compared with the risks of continued smoking.

I know that you don't want to gain a lot of weight. However, let's focus on strategies to get you healthy rather than on weight. Think about eating plenty of fruits and vegetables, getting regular exercise, getting enough sleep, and avoiding high-calorie foods and beverages. Right now, this is probably the best thing you can do for both your weight and your health.

Although you may gain some weight after quitting smoking, compare the importance of this with the added years of healthy living you will gain, your better appearance (less wrinkled skin, whiter teeth, fresher breath), and good feelings about quitting. 


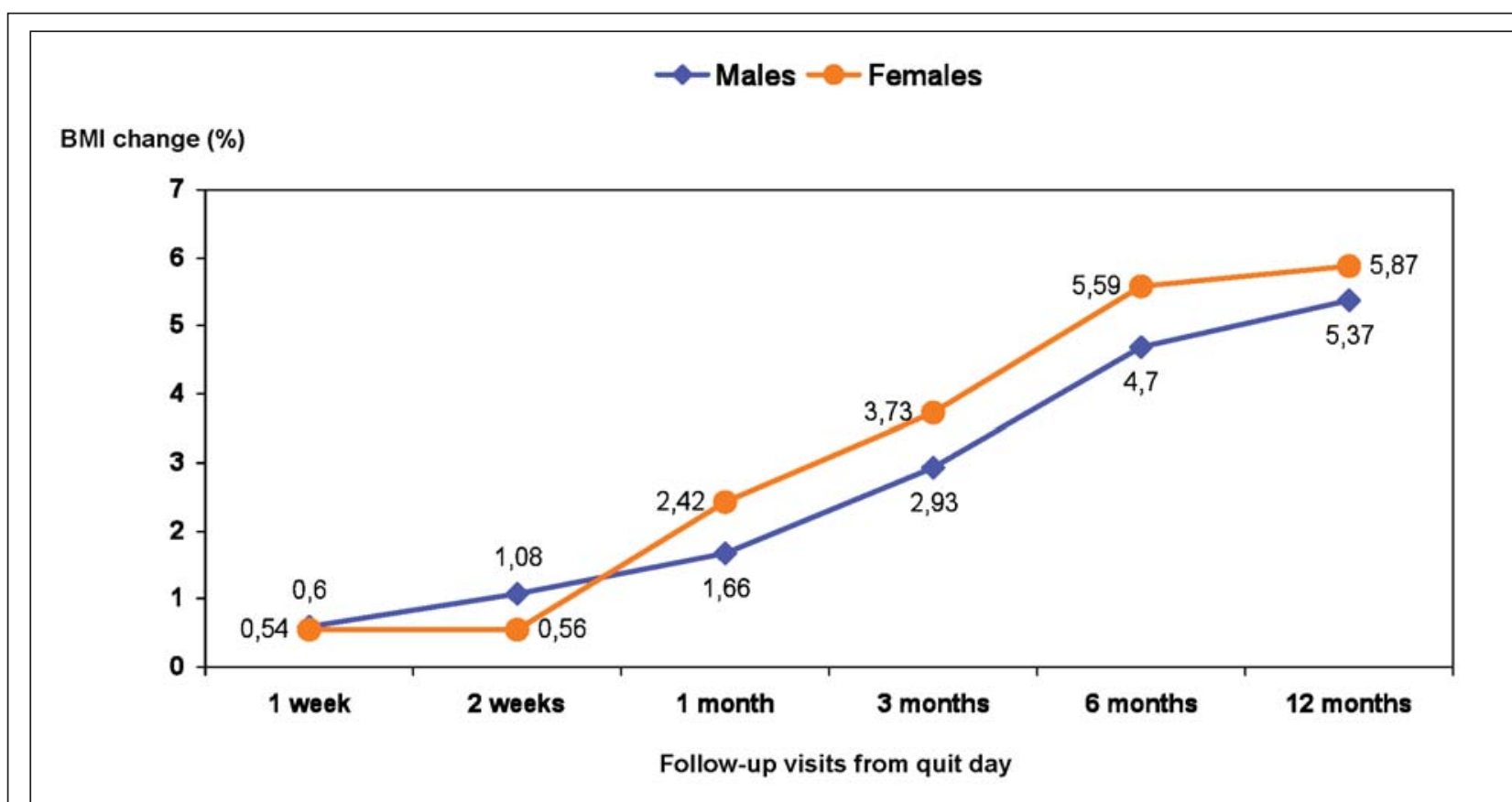

Fig. 1. - Percentage change of BMI from baseline observed at various follow-up visits over 12 months in male and female smokers continuously abstinent from their target quit day. Data from the Smoking Cessation Centre of the University Hospital of Pisa (Italy).

$\mathrm{BMI}=$ body mass index $\left(\mathrm{kg} / \mathrm{m}^{2}\right)$. BMI \% change from baseline was computed as follows: (BMI at follow-up - BMI at baseline) / BMI at baseline $\mathrm{x} 100$. The control visits were performed in the following follow-up periods: 1 week = between 7-12 days from baseline; 2 weeks = 13-19 days; 1 month $=20-69$ days; 3 months $=70-140$ days; 6 months $=141-299$ days; 12 months $=>300$ days .

erating in a Respiratory Unit since 1994, where controlled clinical trials, interventions on specific groups of smokers (e.g. participants in a lung cancer screening project, pregnant women, etc.), and routine interventions are carried out [50-57]. Briefly, pneumologists conduct a programme based on individual counselling and prescription of pharmacotherapy (NRT - in the form transdermal patches, lozenges, inhalers or gums - Varenicline or Bupropion, separately or in various associations). Five visits are scheduled in the first three months after a baseline evaluation, and follow-up visits are planned at 6 and 12 months.

We analysed data provided by 1765 smokers (1025 males and 740 females) who underwent to a smoking cessation programme between January 2001 and May 2007. Figure 1 shows the percentage change of BMI from baseline observed at various follow-up visits over 12 months in smokers continuously abstinent from their target quit day. Both in males and females a higher change in BMI was observed starting from one-month follow-up visit and continued up to 12 months. The distinction between males and female were not statistically different. Even those smokers who had been abstinent for a certain period showed a change in BMI significantly higher than those who had been never abstinent. For example, at the fourth control visit (70-140 days from baseline), the percentage change in BMI was $2.93 \%$ in those male smokers who had been continuously abstinent up to the control visit while it was $1.55 \%$ in those who had been continuously abstinent less than 70 days; the corresponding figures for female smokers were 3.73 and $1.58 \%$. Gaining weight after smoking cessation was significantly related to the duration of continuous abstinence (about 90 gr per each week of abstinence, $p<0.001)$ and the number of cigarettes smoked per day at baseline (about $37 \mathrm{gr}$ per each cigarette smoked per day, $p=0.002$ ) but not to the age of the smoker. The mean absolute gain in weight observed in this study population of smokers was $0.42,1.43,3.66$, and $4.08 \mathrm{~kg}$ at 1 week, 1 month, 6 month and 12 months control visit, respectively, ranging from to a minimum of -6.20 to a maximum of $17.0 \mathrm{~kg}$. Only $6 \%$ of smokers continuously abstinent over 12 months gained more than $10 \mathrm{~kg}$.

\section{Conclusions}

Weight gain after smoking cessation is expected, but only a minority of quitters experience excessive weight gain. In our experience, the mean absolute weight gain was $4 \mathrm{~kg}$ after 12 months of continuous abstinence from smoking. Altogether, the health benefits of smoking cessation far exceed any health risk that may result from weight gain. Physicians should intervene on their weight-concerned smoking patients to promote smoking cessation by offering both behavioural and pharmacological support. Thus, avoiding weight gain would not only remove a barrier to cessation, but also allow for greater health benefits.

\section{References}

1. Adams KF, Schatzkin A, Harris TB, et al. Overweight, obesity, and mortality in a large prospective cohort of persons 50 to 71 years old. $N$ Engl J Med 2006; 355: 763-778.

2. U.S. Department of Health and Human Services. The Health Consequences of Smoking: A Report of the Surgeon General. Atlanta, GA: U.S. Department of Health and Human Services, Centers for Disease Control and 
Prevention, National Center for Chronic Disease Prevention and Health Promotion, Office on Smoking and Health, 2004

3. International Association for the Study of Obesity. www.iotf.org. Accessed: January 2009.

4. Ogden CL, Carroll MD, Curtin LR, McDowell MA, Tabak CJ and Flegal KM. Prevalence of overweight and obesity in the United States, 1999-2004. JAMA 2006; 295: 1549-1555.

5. John U, Hanke M, Rumpf HJ and Thyrian JR. Smoking status, cigarettes per day, and their relationship to overweight and obesity among former and current smokers in a national adult general population sample. Int $J$ Obes (Lond) 2005; 29: 1289-1294.

6. U.S. Department of Health and Human Services. The Health Benefits of Smoking Cessation. U.S. Department of Health and Human Services. Public Health Service. Centers for Disease Control. Center for Chronic Disease Prevention and Health Promotion. Office on Smoking and Health. DHHS Publication No. (CDC) 90-8416, 1990.

7. Flegal KM, Troiano RP, Pamuk ER, Kuczmarski RJ and Campbell SM. The influence of smoking cessation on the prevalence of overweight in the United States. $N$ Engl J Med 1995; 333: 1165-1170.

8. O'Hara P, Connett JE, Lee WW, Nides M, Murray R and Wise R. Early and late weight gain following smoking cessation in the Lung Health Study. Am J Epidemiol 1998; 148: 821-830.

9. Pisinger $\mathrm{C}$ and Jorgensen T. Waist circumference and weight following smoking cessation in a general population: the Inter99 study. Prev Med 2007; 44: 290-295.

10. Klesges RC, Winders SE, Meyers AW, et al. How much weight gain occurs following smoking cessation? A comparison of weight gain using both continuous and point prevalence abstinence. J Consult Clin Psychol 1997; 65: 286-291.

11. Munafo MR, Murphy MF and Johnstone EC. Smoking cessation, weight gain, and DRD4 -521 genotype. Am J Med Genet B Neuropsychiatr Genet 2006; 141B: 398402.

12. Mizoue T, Ueda R, Tokui N, Hino Y and Yoshimura T. Body mass decrease after initial gain following smoking cessation. Int J Epidemiol 1998; 27: 984-988.

13. Williamson DF, Madans J, Anda RF, Kleinman JC, Giovino GA and Byers T. Smoking cessation and severity of weight gain in a national cohort. $N$ Engl $J$ Med 1991; 324: 739-745.

14. Swan GE and Carmelli D. Characteristics associated with excessive weight gain after smoking cessation in men. Am J Public Health 1995; 85: 73-77.

15. Bartholomew HC and Knuiman MW. Longitudinal analysis of the effect of smoking cessation on cardiovascular risk factors in a community sample: the Busselton Study. J Cardiovasc Risk 1998; 5: 263-271.

16. Filozof C, Fernandez Pinilla MC and Fernandez-Cruz A. Smoking cessation and weight gain. Obes Rev 2004; 5: 95-103.

17. Jensen EX, Fusch C, Jaeger P, Peheim E and Horber FF. Impact of chronic cigarette smoking on body composition and fuel metabolism. J Clin Endocrinol Metab 1995; 80: 2181-2185.

18. Ferrara CM, Kumar M, Nicklas B, McCrone S and Goldberg AP. Weight gain and adipose tissue metabolism after smoking cessation in women. Int J Obes Relat Metab Disord 2001; 25: 1322-1326.

19. Hellerstein MK, Benowitz NL, Neese RA, et al. Effects of cigarette smoking and its cessation on lipid metabolism and energy expenditure in heavy smokers. J Clin Invest 1994; 93: 265-272.

20. Neese RA, Benowitz NL, Hoh R, et al. Metabolic interactions between surplus dietary energy intake and cigarette smoking or its cessation. Am J Physiol 1994; 267: E1023-1034.

21. Bamia C, Trichopoulou A, Lenas D and Trichopoulos D. Tobacco smoking in relation to body fat mass and distribution in a general population sample. Int $J$ Obes Relat Metab Disord 2004; 28: 1091-1096.

22. Stamford BA, Matter S, Fell RD and Papanek P. Effects of smoking cessation on weight gain, metabolic rate, caloric consumption, and blood lipids. Am J Clin Nutr 1986; 43: 486-494.

23. Stamler J, Rains-Clearman D, Lenz-Litzow K, Tillotson JL and Grandits GA. Relation of smoking at baseline and during trial years 1-6 to food and nutrient intakes and weight in the special intervention and usual care groups in the Multiple Risk Factor Intervention Trial. Am J Clin Nutr 1997; 65: 374S-402S.

24. Bottai M, Pistelli F, Di Pede F, et al. Longitudinal changes of body mass index, spirometry and diffusion in a general population. Eur Respir J 2002; 20: 665-673.

25. Pistelli F, Bottai M, Carrozzi L, et al. Changes in obesity status and lung function decline in a general population sample. Respir Med 2008; 102: 674-680.

26. Carey IM, Cook DG and Strachan DP. The effects of adiposity and weight change on forced expiratory volume decline in a longitudinal study of adults. Int J Obes Relat Metab Disord 1999; 23: 979-985.

27. Wang ML, McCabe L, Hankinson JL, et al. Longitudinal and cross-sectional analyses of lung function in steelworkers. Am J Respir Crit Care Med 1996; 153: 1907-1913.

28. Wise RA, Enright PL, Connett JE, et al. Effect of weight gain on pulmonary function after smoking cessation in the Lung Health Study. Am J Respir Crit Care Med 1998; 157: 866-872.

29. Chinn S, Jarvis D, Melotti R, et al. Smoking cessation, lung function, and weight gain: a follow-up study. Lancet 2005; 365: 1629-1635; discussion 1600-1621.

30. Wee CC, Rigotti NA, Davis RB and Phillips RS. Relationship Between Smoking and Weight Control Efforts Among Adults in the United States. Arch Intern Med 2001; 161: 546-550.

31. Borrelli B, Spring B, Niaura R, Hitsman B and Papandonatos $\mathrm{G}$. Influences of gender and weight gain on short-term relapse to smoking in a cessation trial. $J$ Consult Clin Psychol 2001; 69: 511-515.

32. Pomerleau CS and Saules K. Body image, body satisfaction, and eating patterns in normal-weight and overweight/obese women current smokers and never-smokers. Addict Behav 2007; 32: 2329-2334.

33. Sepinwall D and Borrelli B. Older, medically ill smokers are concerned about weight gain after quitting smoking. Addict Behav 2004; 29: 1809-1819.

34. Pomerleau CS, Zucker AN and Stewart AJ. Characterizing concerns about post-cessation weight gain: results from a national survey of women smokers. Nicotine Tob Res 2001; 3: 51-60.

35. Berg CJ, Park ER, Chang Y and Rigotti NA. Is concern about post-cessation weight gain a barrier to smoking cessation among pregnant women? Nicotine Tob Res 2008; 10: 1159-1163.

36. Pisinger $\mathrm{C}$ and Jorgensen $\mathrm{T}$. Weight concerns and smoking in a general population: the Inter99 study. Prev Med 2007; 44: 283-289.

37. Copeland AL, Martin PD, Geiselman PJ, Rash CJ and Kendzor DE. Smoking cessation for weight-concerned women: group vs. individually tailored, dietary, and weight-control follow-up sessions. Addict Behav 2006; 31: 115-127.

38. Alberg AJ, Carter CL and Carpenter MJ. Weight gain as an impediment to cigarette smoking cessation: a lingering problem in need of solutions. Prev Med 2007; 44: 296-297. 
39. Perkins K. Issues in the prevention of weight gain after smoking cessation. Ann Behav Med 1994; 16: 46-52.

40. Hall S, Tunstall C, Vila K and Duffy J. Weight gain prevention and smoking cessation: cautionary findings. Am J Public Health 1992; 82: 799-803.

41. Perkins KA, Marcus MD, Levine MD, et al. Cognitivebehavioral therapy to reduce weight concerns improves smoking cessation outcome in weight-concerned women. J Consult Clin Psychol 2001; 69: 604-613.

42. Kawachi I, Troisi RJ, Rotnitzky AG, Coakley EH and Colditz GA. Can physical activity minimize weight gain in women after smoking cessation? Am J Public Health 1996; 86: 999-1004.

43. Marcus BH, Albrecht AE, King TK, et al. The efficacy of exercise as an aid for smoking cessation in women: a randomized controlled trial. Arch Intern Med 1999; 159: 1229-1234.

44. Taylor AH, Ussher MH and Faulkner G. The acute effects of exercise on cigarette cravings, withdrawal symptoms, affect and smoking behaviour: a systematic review. Addiction 2007; 102: 534-543.

45. Fiore MC, Jaén CR, Baker TB and et al. Treating Tobacco Use and Dependence: 2008 Update. Clinical Practice Guideline. Rockville, MD: U.S. Department of Health and Human Services. Public Health Service. May 2008, 2008.

46. Cahill $\mathrm{K}$ and Ussher M. Cannabinoid type 1 receptor antagonists (rimonabant) for smoking cessation. Cochrane Database Syst Rev 2007: CD005353.

47. Toll BA, Leary V, Wu R, Salovey P, Meandzija B and O'Malley SS. A preliminary investigation of naltrexone augmentation of bupropion to stop smoking with less weight gain. Addict Behav 2008; 33: 173-179.

48. Spring B, Wurtman J, Wurtman R, et al. Efficacies of dexfenfluramine and fluoxetine in preventing weight gain after smoking cessation. Am J Clin Nutr 1995; 62: 1181-1187.
49. Borrelli B, Spring B, Niaura R, Kristeller J, Ockene JK and Keuthen NJ. Weight suppression and weight rebound in ex-smokers treated with fluoxetine. J Consult Clin Psychol 1999; 67: 124-131.

50. Paoletti P, Tonnesen $\mathrm{P}$ and Rodriguez-Roisin R. CEASE (Collaborative European Anti-Smoking Evaluation). A challenging multicenter trial organized by the European Respiratory Society. Chest 1993; 103: 13171319.

51. Paoletti P, Fornai E, Maggiorelli F, et al. Importance of baseline cotinine plasma values in smoking cessation: results from a double-blind study with nicotine patch. Eur Respir J 1996; 9: 643-651.

52. Tonnesen P, Paoletti P, Gustavsson G, et al. Higher dosage nicotine patches increase one-year smoking cessation rates: results from the European CEASE trial. Collaborative European Anti-Smoking Evaluation. European Respiratory Society. Eur Respir J 1999; 13: 238-246.

53. Carrozzi L, Pistelli F, Fornai E, Desideri M, Viegi G and Giuntini C. Smoking cessation clinic: an Italian experience. Monaldi Arch Chest Dis 2000; 55: 502-505.

54. Carrozzi L, Pistelli F and Viegi G. Pharmacotherapy for smoking cessation. Ther Adv Respir Dis 2008; 2: 301317.

55. Pistelli F, Aquilini F, Tavanti L, et al. Smoking cessation over the first year of follow-up in a lung cancer screening with spiral chest CT scan (Italung_CT study). Eur Respir J 2007; 30 (suppl. 51).

56. Cosci F, Corlando A, Fornai E, Pistelli F, Paoletti P and Carrozzi L. Nicotine dependence, psychological distress and personality traits as possible predictors of smoking cessation. Results of a double-blind study with nicotine patch. Addict Behav 2008.

57. Cosci F, Schruers KR, Pistelli F and Griez EJ. Negative affectivity in smokers applying to smoking cessation clinics: a case-control study. Depress Anxiety 2008; 0: 1-7.

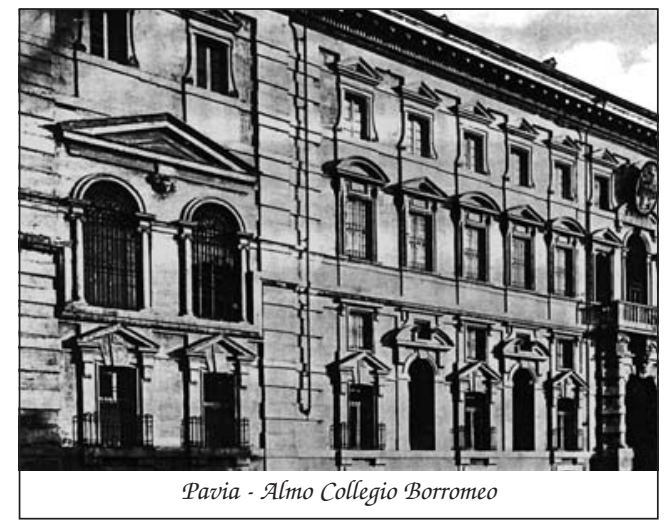

